\title{
Exploring adaptation and agency of mothers caring for disabled children in an urban settlement in South Africa: A qualitative study
}

\author{
Elise J. van der Mark ${ }^{\mathrm{a}, *, 1}$, Ina Conradie ${ }^{\mathrm{a}, \mathrm{b}}$, Christine W.M. Dedding ${ }^{\mathrm{c}, 2}$, Jacqueline E.W. Broerse \\ ${ }^{a}$ Institute for Social Development (ISD), University of the Western Cape, Robert Sobukwe Road, Private Bag X17, Bellville, Cape Town 7535, South Africa \\ ${ }^{\mathrm{b}}$ Institute for Social Development (ISD), Faculty of Economic and Management Sciences, University of the Western Cape, School of Government Building, Robert Sobukwe \\ Road, Private Bag X17, Bellville, Cape Town 7535, South Africa \\ ${ }^{\mathrm{c}}$ Athena Institute, Faculty of Earth and Life Sciences, VU University Amsterdam, De Boelelaan 1085, 1081 HV Amsterdam, the Netherlands
}

A R T I C L E I N F O

\section{Keywords:}

Mothers

Care

Adaptation

Disabled Children

Resource-Poor

South Africa

\begin{abstract}
A B S T R A C T
Mothers of disabled children who are living in poverty face multiple interlinked disadvantages in relation to gender, care, disability, and poverty. Yet, their experiences have been largely neglected in academic literature. This study explores how mothers from a poor urban settlement in South Africa manoeuvre, adapt, act and react in such a difficult context, and how they maintain or improve their own and their family's wellbeing. Our qualitative research with 30 mothers shows women's adaptation and agency in the trade-offs they make. Fuelled by social discrimination and abuse, mothers prefer to focus solely on the child, its care and the household in order to keep themselves and their child safe. Despite providing certain benefits that mothers value, these preferences perpetuate or indeed worsen their position in society, as they reinforce traditional gender structures and render them invisible to policymakers. This poses serious challenges for women's empowerment and gendersensitive poverty-reduction policies.
\end{abstract}

\section{Introduction}

Women worldwide commonly bear the main responsibility of caring for a child with disabilities, which has significant implications for their own wellbeing and development. Despite the extensive academic literature on the experiences of mothers of disabled children in wealthy countries, the lives of poor women caring for disabled children have been largely neglected. The scant existing information suggests a tremendously difficult existence in which mothers face various financial, social, psychological and physical problems (e.g. Sandy, Kgole, \& Mavundla, 2013; Van der Mark, Conradie, Dedding, \& Broerse, 2017). Multiple interlinked disadvantages relating to gender norms, care, disability and poverty, create constant challenges for women.

However, borrowing Beresford's (2016) phrase, 'misery accounts' are not sufficient as we also need to understand how mothers manoeuvre, adapt, act and react in such a context. Acknowledging and understanding the carer's perspectives, priorities and actions is an important part of amplifying grassroots women's voices in establishing policy and of the ongoing effort to recognize women as active agents with 'the capacity to make decisions and shape one's world in accordance with what one cares about', rather than viewing them as passive victims (Khader, 2011, 31).

Moreover, understanding mothers' daily lives, choices, priorities and actions is essential for policy and practice in women's empowerment and gender equity in a context of poverty. For instance, education programmes for women might not reach and benefit these carers if they do not address their needs and daily reality, for example when a mother prioritizes her child's education over her own. This article presents insights into how mothers of a disabled child manoeuvre, adapt, act and react by drawing on the lives of mothers from an impoverished part of the urban settlement of Khayelitsha near Cape Town in South Africa. Our broader aim is to contribute to the global effort to listen to women's voices and ameliorate their wellbeing.

\section{Caring for a disabled child in a resource-poor context}

To date, little research specifically studies mothers of a disabled child living in poverty. Existing current studies suggest that "caring for a

\footnotetext{
* Corresponding author.

E-mail addresses: e.j.vander.mark@vu.nl (E.J. van der Mark), cconradie@uwc.ac.za (I. Conradie), c.dedding@vumc.nl (C.W.M. Dedding), j.e.w.broerse@vu.nl (J.E.W. Broerse).

${ }^{1}$ Present affiliation: VU University Amsterdam, the Netherlands.

${ }^{2}$ Present affiliation: VU Medical Centre, Amsterdam, the Netherlands.
} 
disabled child is... a time-consuming, expensive and isolating experience in addition to the physical and psychological effects' (Van der Mark et al., 2017, 1193). Accordingly, mothers from low-income contexts in countries such as Pakistan and Namibia commonly struggle to care for their child (Qayyum, Lasi, \& Rafique, 2013; Taderera \& Hall, 2017). The poor availability, accessibility and affordability of services and transport often leads them to become more self-reliant, such as learning to give physiotherapy, to administer medication or to make assistive devices, for instance in Uganda (Hartley, Ojwang, Baguwemu, Ddamulira, \& Chavuta, 2005). Moreover, they limit their efforts to seek medical care and/or professional advice and information. Likewise, several studies, such as those on Ecuador and Tanzania, illustrate that mothers seldom request and receive social support due to the social stigma attached to disability and poverty (Huiracocha-Tutiven, Orellana-Paucar, Brito, \& Blume, 2017; McNally \& Mannan, 2013). Lastly, in many countries religious faith seems to play a role for mothers to acquiesce in their child's disability, their low living standards and social constraints (e.g. in Nicaragua, Matt, 2014; in Sri Lanka, Wijesinghe, Cunningham, Fonseka, Hewage, \& Østbye, 2015).

According to seven articles on carers in South Africa, they encounter similar constraints on their ability to ensure their own and their family's general wellbeing. Disabled children and their families are among the most marginalized in South Africa (DSD, 2016), and especially women are affected as they continue to be seen and act as the primary carers. Despite its progressive constitution regarding egalitarianism, e.g. social assistance and free health care, South Africa is a deeply divided and unequal society (Seekings \& Nattrass, 2015). Class, ethnic and gender inequalities affect millions of lives and are sustained by the apartheid legacy, a strong patriarchal culture, and pervasive (disability) stigma (DSD, 2016; Seekings, 2010). Notwithstanding the ongoing efforts of numerous non-government organizations (NGOs) addressing social inequalities and poverty, policies and programmes largely fail to assist disabled children and their families (DSD, DWCPD, \& UNICEF, 2012).

First, caring for their disabled child restricts mothers' employment opportunities. This creates a substantial financial hardship, which in turn perpetuates the low living standards regarding housing, clean water, electricity, clothing, food, and sanitation (Hemming \& Akhurst, 2009; Sandy et al., 2013). Moreover, many South African mothers report receiving inadequate emotional, financial and practical support from family and friends, and also struggle to use (para-) medical, psychological, respite and educational services (Mathye \& Eksteen, 2015; Pretorius \& Steadman, 2017). Indeed, several studies indicate that mothers even refrain from seeking informal or formal support and the resulting social isolation is frequently reported (Philpott \& McLaren, 2011; Saloojee, Phohole, Saloojee, \& Ijsselmuiden, 2007). In Khayelitsha, our earlier study also pointed toward a notion of sole care in which mothers see themselves as the only and best carer who has to do 'her job' (der Mark, 2018). Overall, many mothers experience various interconnecting personal, social and political factors that perpetuate their deprivation.

In this context of interlinked disadvantages women make choices, take action, and manoeuvre on a daily basis, based on their own reasoning, competences, priorities and values. The main question we address in this study is: How do these women try to maintain or improve their own and their family's wellbeing in such a context?

\section{Agency and adapted preferences}

To answer this question, we employ the concept of agency. The theorisation of agency has developed over a long period of time in several academic disciplines such as economics, psychology and sociology. 'Many disciplines reacted against structuralism's failure to take into account the actions of individuals' (Ahearn, 2000, 12). Relating to poor women's agency, economist and philosopher Amartya Sen's wellknown capabilities approach is most relevant (1988). Herein, agency pertains to the autonomy and personal liberty to initiate and take reflective action upon whatever goals or values a person regards as important (Alkire, 2008; Conradie, 2014). In this article we adhere to this conceptualization of agency. However, with only this definition we might overlook expressions of agency which are self-depriving, such as refraining from seeking medical support. Moreover, the conditions shaping these actions might easily be neglected.

To avoid this pitfall, we also adopt the Adaptive Preferences (APs) concept, which has been widely used in feminist and development theories since the 1980s. Social and political theorists such as Sen (1988), Nussbaum (2001) and Elster (1987) applied it to explain strategies and behaviours of deprived and/or oppressed people that perpetuate or worsen their deprivation. In feminist philosophy it has been mainly used to understand women's self-depriving behaviours in the context of (patriarchal) oppression, such as choosing not to pursue further education believing a future husband will provide.

Common conceptions of APs imply that a person with self-depriving preferences has a 'deficit in autonomy and/or self-worth'. It is understood as a person 'lowering the bar for oneself' as a result of socialization and resignation. Individuals with APs are thus seen as victims of unfortunate circumstances. It is hard to see how this concept then can assist in understanding mothers' agency in their daily lives. Serene Khader (2011), however, convincingly offers a conceptualization of adaptive preferences which acknowledges that people often accept and/or perpetuate their own deprivation and simultaneously can be active, exercise autonomous choice and be reflective agents. She states that having APs does not immediately render someone having a global deficit in autonomy, self-worth or self-entitlement, and thus agency. Rather, Khader (2013) argues, APs which are fuelled by damaging conditions tend to result from either a selective lack of self-entitlement, forced trade-offs or factual misperception.

To illustrate, we use the earlier-mentioned example where a mother prioritizes her son's education over her own. She might be socialized into believing that married women and mothers should not further their education (lack of entitlement to self-development) but values her responsibility as a mother to advance her son's opportunities (self-entitlement regarding good motherhood) (selective value distortion). Or she might feel, due to financial constraints, that she has to sacrifice wellbeing in one domain (her own education) in order to flourish in another (securing income later in life through the child's employment) without any loss of self-entitlement (forced trade-off). Or she might overestimate the opportunity costs (time and money) of advancing her own education due to lack of information and adapt her behaviour accordingly (factual misperception).

These three forms of adaptive preferences elucidate Khader's claim that a person cannot be viewed as lacking agency or self-worth based solely on the fact that she has self-depriving preferences. Though there may be evidence of people adapting to damaging conditions because of a global lack of self-value and autonomy, Khader (2013) stresses that most APs portray one or a combination of the above causes. Khader's concept thus encourages us to scrutinize certain behaviours which would suggest the person is merely a victim of damaging circumstances, and understand how these behaviours are embedded in a disadvantaged context, while simultaneously fuelled by a person's underlying values, reasoning and agency. Besides the relevance of this approach for social justice (including women as active agents), it reduces the risk of women's empowerment programmes being inappropriate and ultimately unsuccessful. It is easy to see how a conscientization programme about gender inequality could benefit the mother in the first case, but might well fail in the second and third example. Understanding mothers' APs thus becomes a valuable tool for a broader political project, namely to effectively 'combat marginalisation and oppression' (Terlazzo, 2016, 210).

\section{Methods}

This study is part of a two-year participatory action-research (PAR) 
with mothers of disabled children from a poor urban settlement in South Africa. The intervention results will be reported separately.

\section{Setting}

Our research site Khayelitsha is an urban, fairly isolated, settlement $25 \mathrm{~km}$ from Cape Town with approximately 400,000 primarily black African residents. Most residents are from rural areas who came to Khayelitsha after the abolition of apartheid's 'influx control' law. Violent crime, gangsterism, drug abuse and overcrowding scourge Khayelitsha (Brunn \& Wilson, 2012; Seekings, 2013). 'Poverty is widespread, with the majority of Khayelitsha's residents living cheek by jowl in overcrowded shack settlements, accessing electricity illegally, sharing communal water taps, and relying on grossly inadequate sanitation arrangements (such as outside portable toilets)' (Super, 2015, 1). It is estimated that over $45 \%$ of residents are unemployed (Seekings, 2013) and the last census in 2011 found that the median annual income was R20 $000^{3}$ per household. Some social and medical services are available, although frequently overstretched, ineffective and inaccessible due to the number of patients (Seekings, 2013). Stigma and abuse of children with disabilities is reported to be pervasive, while mothers face discrimination and abuse as they are often blamed for giving birth to a disabled child (DSD, 2016). This exacerbates the problematic context for the 30 mothers whose adaptation and agency we explore in this article.

\section{Sampling procedures}

Purposive sampling was used to recruit carers. Considering safety issues in Khayelitsha for the researchers, first access was gained with caregivers that were making use of a reputable day-care centre for disabled children, ${ }^{4}$ through the help of DICAG, a national DPO (Disabled Persons Organisation) focussing on disabled children. Acknowledging the fact that access to services is often limited for caregivers in South Africa (DSD, DWCPD, \& UNICEF, 2012), parents from the wider community were subsequently invited to participate through word of mouth and the help of female community leaders we contacted. The inclusion criteria were for the respondent to be (1) a female resident of Khayelitsha, (2) over the age of 18 , and (3) the primary carer of a child with any type of disability preferably under the age of 18 (not necessarily the biological mother).

\section{Study respondents}

Thirty female carers of a disabled child participated, including 26 biological mothers, three grandmothers and one sister. ${ }^{5}$ Seven women were using the day-care centre; the remaining 23 came from the wider community. Four of the children were over 18 years, the other children's ages ranged from 1 to 18 years.

\section{Data collection}

Data collection occurred between September 2015 and December 2016, during which bi-weekly group sessions (approximately $2.5 \mathrm{~h}$ ) were organized between the main researcher and the respondents $(n=30)$. Twenty-four sessions revolved around direct data collection, the remaining sessions concentrated on the design and implementation of the action project (which provided indirect data through observation). In addition, the main researcher conducted participant

\footnotetext{
${ }^{3} \mathrm{R} 20.000$ (South African Rand) was approximately $£ 990,=$ and $\$ 1275,=$ at the time of research.

${ }^{4}$ See www.sibongile.org.

${ }^{5}$ For readability purposes, the term mothers refers to all carers throughout this article, unless stated otherwise.
}

observation by spending much informal time with the women through group activities such as lunches and home visits. This helped to establish trust and contributed to a deeper understanding of these mothers' lives.

During 12 data-collection sessions, creative and participatory methods were used to explore mothers' daily activities and contexts. Creative methods included drawing a daily pie-chart indicating time spent on their activities; ranking easiest and hardest daily activities; and drawing social atoms specifying social support received. The visual products served as a starting point for more in-depth discussions. In addition to the creative sessions, 12 group sessions discussed emerging or important topics and issues, e.g. resignation and domestic abuse.

Following the nature of a PAR project - and respecting the complex daily lives of the participants, mothers' attendance was fluid and flexible. They could get involved in or withdraw from the project at any stage. In total, 30 mothers participated in one or more of the direct data-collection sessions: six attended 10 or more sessions; seven participated in between six and nine sessions; nine joined between two and five times; and eight joined only one session. Attendance ranged from four to 14 participants, with an average of eight. If motives were shared for non-attendance, household responsibilities, sick children and family ritual obligations were mostly mentioned.

Furthermore, 15 semi-structured interviews (based on voluntary response from the participants) were conducted by the main researcher until initial data saturation. Twelve interviews and all group sessions were performed in the local language isiXhosa. Ad-hoc, summative translation for the main researcher was provided by a female staff member from the day-care centre who the mothers indicated to be most comfortable with. The other three interviews were in English as the respective mothers indicated being comfortable and able to do so. All interviews and group sessions were tape-recorded. Observational journal notes on all group sessions supplemented the data.

As the main researcher has a white western background, promoting cultural sensitivity and local relevance of the study was vital. Five measures were taken before and during the research. Two local female advisors were recruited; an academic and a Khayelitsha-born NGO director. A pilot session with 10 isiXhosa female carers of disabled children provided valuable information on relevant concepts for the researcher at the start (not included in data analysis), and several professional and academic experts were consulted for advice throughout the project. Moreover, the translator's cultural, linguistic and religious sensitivity, and her experience with mothers and their disabled children, proved invaluable.

Scientific validity was further enhanced by a systematic research administration including descriptions of context(s), activities, and research procedures, data-triangulation, informal discussion with disability professionals and academics, respondents' involvement in review and analysis, and critical discussions with the research group.

\section{Data analysis}

Open content analysis was applied to provide for a comprehensive and detailed understanding of adaptation and agency in the mothers' complex daily lives. This type of analysis combines the perceptions of the 'insider' mothers, and the 'outsider' researchers, and helps to get an in-depth understanding of context-specific experiences, attached meanings and behaviour (Geertz, 1973).

As translation during interviews and groups sessions was merely summative for the researcher, additionally, for verification and analysis purposes, two native isiXhosa language scholars translated the recordings of interviews and group sessions into English while transcribing verbatim in English. An independent third scholar assessed the transcriptions at random for correctness, accuracy and quality. The computer programme Atlas.ti was used for data analysis of these transcriptions. Data collection and data analysis took place simultaneously to develop emerging themes. Each analytical category was discussed 
further in group sessions with the respondents to expand our understanding of these categories and their relations.

During the first phase of the overall PAR project, focusing on understanding women's daily realities, the solitary responsibility of care emerged as a central theme - how women tend to care for their child on their own in isolation. The question of how and why women manoeuvre, adapt, act and react as they do followed and was further explored with the respondents. Selective content analysis was then applied, providing data for the present article, to understand mothers' adaptation and agency. Further analysis, categorization and discussion in the research group resulted in two main categories, presented in the Results section.

\section{Ethics}

Ethical approval was obtained from the Senate Research Ethics Committee of the University of the Western Cape, South Africa (No. 15/ 2/15). In Participatory Action Research informed consent is a two-way process. It can be seen as a mutual and ongoing negotiation between the researcher and the participant on 'the terms and conditions of their joint efforts' (Khanlou \& Peter, 2005, 2337), which feeds into so-called informed process consent. In this study continuous transparency about the purpose and aim of the research (gaining a contextual understanding of the women's lives), the purpose and aim of the research for the participants (social change and empowerment), the timeframe, the participants' rights, benefits, risks, expectations and limitations was crucial. Further, before the interviews and group sessions, respondents gave written informed consent and their rights to remain silent or withdraw from the project were explained. Anonymity and confidentiality were guaranteed by using pseudonyms. Efforts were made to reduce participation barriers by widening sampling procedures, creating flexible schedules, choosing proximate research venues and providing for childcare (Minkler et al., 2002). Due to the sensitivity of the research topic, it was anticipated that social and psychological problems would arise. For this reason, prior to the project, the main researcher established contact with several local organizations and service providers to set up a support network. Several women indeed needed counselling. The main researcher contacted the relevant services and assisted the women in obtaining access to legal assistance, family counselling and safe houses, among others. At the time of writing, this support network remains in place.

\section{Results}

Mothers' experiences revealed two major adaptive preferences, namely keeping their child at home and minimizing the search for external support. These preferences are both forced trade-offs as a result of harsh conditions and mothers consider them self-depriving. In the following paragraphs, we will show mothers' deliberations and agency in developing their preferences. Before we go into this in detail, we briefly introduce the mothers below.

\section{The mothers}

The participating women come from diverse backgrounds (see Table 1).

Young single mothers with one child as well as mothers with large families and grandmothers participated. The children were of various age groups with different types of disabilities. Not all children had been officially diagnosed, but $50 \%$ have cerebral palsy according to their mother. ${ }^{6}$ Most of the mothers had no education beyond secondary

\footnotetext{
${ }^{6}$ In South Africa, cerebral palsy is one of the most widespread forms of disability. Mothers assumed their child to have cerebral palsy when it had both physical and psychological impairments.
}

school, lived without a spouse, and depended on the government's Care Dependency Grant. ${ }^{7,8}$

\section{Mothers' adaptation and agency}

Both adaptive preferences, keeping their child at home and minimizing the search for external support, are discussed below to shed light on 1) the reasons for how these preferences developed; 2) the detrimental consequences of these preferences; 3 ) the benefits of and trade-offs made in these preferences; and 4) the ways mothers attempt to mitigate the detrimental consequences.

\section{Keeping their child at home: reasons}

Almost $80 \%$ of the participants provide 24 -hour care for their child at home. Initially, all these mothers tried to find schooling for their child. They talk about endless journeys to potential schools and care facilities, and requesting information and assistance regarding education from social workers in particular. Most mothers encounter schools and day-care centres that they say neglect and/or severely abuse their child. This motivates most of them to eventually keep their child at home.

I have taken her to normal crèches before I realized something was wrong with her and I noticed they were not treating her well. So, I decided she should be at home until there's a place suitable for her, then I can take her to that place. $^{9}$

(Aphiwe)

I noticed back then kids were not supervised properly by teachers. They would be rough on kids. You would notice they don't care about the child. A child would come back home without any nappy; a child would come back bruised. No one reported a broken leg or what. So, I couldn't let him go to those schools.

(Fundiswa)

At Alawi [day-care centre] I discovered they are not giving him treatment. I wrote a letter requesting them to give him his treatment. Nothing changed. So, I sent him to Red Cross and I told his doctor about the situation that since he is defaulting treatment, he gets worse on his seizures. So, I said to the doctor: 'I will not send him there'... Now I stay with him all day to take care of his health.

(Lihle)

These quotes vividly portray conscious reflection and agency in seeking proper schooling, and in eventually deciding to keep their child at home. The experienced or anticipated abuse and neglect is determinant.

\section{Keeping their child at home: consequences}

Caring for their child full-time greatly hampers mothers' opportunities to earn a living and be financially independent. As Notumato describes:

I can't even get a job because I am always looking after my child. I never worked ever since I gave birth to my son, so now I am dependent on my other children.

\footnotetext{
${ }^{7}$ The Care Dependency Grant is intended for low-income caregivers of severely disabled children between 0 and 18 years old who need full-time care (SASSA, 2016).

${ }^{8}$ At the time of research, this grant was set at 1410 South Africa Rand (ZAR) per month ( = approx. $£ 70$ and $\$ 90$ ). With a poverty line set in the same year at ZAR 779 (= approx. $£ 38$ and \$50) per person per month (based on 2011 prices), it is clear the vast majority of these mothers and their families live below it (STATS SA, 2015).

${ }^{9}$ All quotes are drawn from either a one-on-one interview with a mother from the core group or from a comment from one of the mothers during a group session. First name pseudonyms are in isiXhosa.
} 
Table 1

Characteristics of participating carers and their children.

\begin{tabular}{|c|c|c|c|c|c|c|}
\hline Carer & & & $\#$ & Child & & $\#$ \\
\hline \multirow[t]{6}{*}{ Age } & & $21-30$ & 6 & Age & $0-5$ & 8 \\
\hline & & $31-40$ & 9 & & $6-10$ & 8 \\
\hline & & $41-50$ & 6 & & $11-15$ & 8 \\
\hline & & $51-60$ & 4 & & $16-20$ & 2 \\
\hline & & $>61$ & 3 & & $21-25$ & 4 \\
\hline & & Missing & 2 & & & \\
\hline \multirow{3}{*}{\multicolumn{2}{|c|}{ Relation to child }} & Mother & 26 & Gender & Boy & 17 \\
\hline & & Grandmother & 3 & & Girl & 13 \\
\hline & & Sister & 1 & & & \\
\hline \multirow[t]{6}{*}{ Marital status } & & Single & 10 & Type of disability (in carers words) & Cerebral palsy & 16 \\
\hline & Relationship, & Not living with partner & 5 & & Cannot walk, talk, sit & 5 \\
\hline & Relationship, & Living with partner & 10 & & Cannot walk & 1 \\
\hline & & Divorced & 1 & & Down syndrome & 1 \\
\hline & & Widowed & 4 & & Blind & 1 \\
\hline & & & & & Slow learner & 1 \\
\hline \multirow[t]{5}{*}{ Highest level of education } & & Primary & 5 & & Special need & 1 \\
\hline & & Secondary & 21 & & Spinal cord injuries & 1 \\
\hline & & Vocational training & 1 & & Left side doesn't work & 1 \\
\hline & & College & 1 & & Prader-Willi syndrome & 1 \\
\hline & & Missing & 2 & & Mental disability and seizures & 1 \\
\hline \multirow[t]{2}{*}{ Number of household members } & & Mean & 5,1 & & & \\
\hline & & Median & 5 & & & \\
\hline \multirow[t]{4}{*}{ Average monthly income (ZAR) } & & $<2000( \pm £ 98,=)$ & 17 & & & \\
\hline & & $2001-4000$ & 6 & & & \\
\hline & & $>4000( \pm £ 195,=)$ & 1 & & & \\
\hline & & Missing & 6 & & & \\
\hline \multirow[t]{5}{*}{ Most important source of income } & & Own job & 5 & & & \\
\hline & & Own income generating activities & 2 & & & \\
\hline & & Other household member's job & 4 & & & \\
\hline & & Learnership & 1 & & & \\
\hline & & Social grant & 18 & & & \\
\hline
\end{tabular}

Likewise, mothers' mobility and psychological and physical health are affected. Nobomi explains:

It is because you see your child suffering and you want to constantly watch them so that nothing bad happens to them. As a result, that also has a bad effect on your own health.

During an informal lunch at Lulama's shack, the physical ordeal is evident as she lifts her severely disabled 14-year-old grandson in and out of the plastic bathtub (placed on her bed) and then carries him to his bed. For a physically fit person this would be challenging, let alone for a 65-year-old with arthritis. She indicates she is in pain but determined to proceed with his twice-weekly baths.

As most mothers care for their child $24 / 7$ and therefore face constrained income and restricted mobility, they constantly have to prioritize certain basic needs over others. Meeting basic needs becomes erratic and a matter of inner debate, as seen, for example, in Olwethu's and Thandiwe's narratives below.

Our house is not $100 \%$. In my case, what I would do is, I would prioritize. I need to try and protect my children from the rain, from it coming inside. But I have no money. So, what I'd do is, I'd put a bucket because it's not going to rain forever. That way I can at least buy food.

You see there are times here at the house there will be nothing [food] because one has got to buy electricity... I will get darker because of the stress. I wish there could be everything for the one who is disabled. I wish there is nothing that runs off mid-month for him.

\section{Keeping their child at home: benefits and trade-offs}

Keeping their child at home due to experienced or expected neglect at schools thus perpetuates or even deepens mothers' deprivation. At the same time, many mothers indicate benefiting from having their child at home in terms of self-esteem, self-respect, pride and social recognition.

I like caring for my child. This is my child. There is no one who can take care of this baby, so it is important to give care to this child, not another person. It is important for us to love them all the time. We have patience and give them love because God chose to give them to us.

(Buhle)

If they see you look after your baby, they are going to respect your baby. But if the mother is not respecting the baby, they are not going to respect the baby. If you always look after your baby, you must stay at home, eat and wash, always keep your baby clean, then they are going to respect your baby.

(Ndiliswa)

Thus, flourishing in some domains (income, meeting basic needs and personal wellbeing) is sacrificed for flourishing in others (self-respect and social recognition). These accounts demonstrate that their personal norms and values (being a faithful Christian, being a good mother) are powerful drivers for this trade-off. In addition, a trade-off is made for their child. All mothers highly value education for their child, as they narrate during a group session:

We have to make sure they get an education. Even if they are unable to write, they must at least learn how to use their hands. Anything that will be able to help them take care of themselves.

(Lulama)

Nevertheless, they all regard their child's freedom from discrimination and abuse as far more important than education - or income, meeting basic needs and personal wellbeing- which motivates them to keep the child at home.

Nine mothers were able to get their child placed at the day-care centre considered the best in Khayelitsha $(n=7)$, or one other reasonable respite care facility in the area $(n=2)$. These mothers say these centres provide good to excellent care for their children, but the choice 
still brings anxiety, worry and stress.

It is always not an easy feeling when you leave the child even if it is at school because one would have thought that the person taking care of this baby does not have a disabled child so it is going to be difficult for them to understand; and they will get very easily irritated.

(Bongani)

Moreover, though these mothers have more time to invest in earning an income, they face the same daily issues regarding, for example, meeting basic needs and personal wellbeing due to the general poverty in which they live and particularly low wages. The scales might just tip a little less far for them.

\section{Keeping their child at home: mitigation}

Apart from the necessary trade-offs, mothers' agency is evident in not passively undergoing and accepting the damaging consequences of caring for their child full time. In fact, they show resilience and ingenuity in mitigating these. First, all mothers make major efforts to obtain their right to social security (such as the Care Dependency Grant). Overcoming the bureaucratic, financial and transport barriers to obtain a social grant is a significant task for most. To be able to visit government offices, mothers are, for example, willing to leave their child with an untrustworthy neighbour, or as Nodende explains: 'I would borrow the money. I would go to people and ask them to borrow me money [to hire a car]'

Second, to make ends meet in a context of unreliable, inaccessible or irregular income, some women develop ad-hoc strategies to access more cash. Several mothers refer to seeking 'piece jobs': one-day jobs such as cleaning or hair dressing, usually to replace someone else. Ndiliswa sells her own clothing in times of financial need. Others occasionally borrow money from extended family or neighbours in order to buy food. Zimkhitha says: 'I will negotiate with the person I owe. I would tell them I will give them what I will probably have at month end. I will pay it bit-by-bit until I paid all of it back'. Over the course of the project, several women also approached the researcher to assist with money for items such as porridge and clothing for their child. A few women state having set up income-generating activities such as selling ice-cream, sweets and paraffin. As Thozoma recounts: 'Because I don't want to depend on his [her husband's] money and on whenever he feels like giving it to me'. It is important to note, however, they choose to engage in these activities only if they can be conducted from home.

Lastly, the child's limited development when s/he is not attending a school or day-care centre is mitigated by educating and exercising their child themselves. Funeka explains:

As a mother I exercise her, and play with her... The child will not develop [without support] so I decided to do what I was told at the $\mathrm{CP}$ clinic. I must be a happy mother and play with the child, love and support the child.

\section{Minimizing their search for external support: reasons}

A second preference all mothers describe in great detail is their tendency to minimize their search for social and medical support. They report having gradually retreated from the 'outside' world.

We choose to live different than others. We create a small world of our own. Just us and our child. We keep quiet, ignore others, and live our lives in our home.

\section{(Nomthandazo)}

Many mothers curb their relations with friends and family after the child is born. Others refrain from attending church, being involved in church committees, or participating in community activities such as festive celebrations. Time constraints and round-the-clock care play a role in mothers moderating their social relations. Bongani, one of the job-holding mothers, recounts:
I only go to church sometimes, because I want to spend quality time with her on Sundays. I must wash her and take care of her... A day gets short.

Moreover, many mothers argue that they prefer not to subject themselves and their child to generally negative responses. Zimkhitha and Funeka share their stories, which are recognized by many others:

I stopped taking my child outside because kids throw stones at him. They once threw a stone at him and it luckily hit the wheelchair instead of him. I just knew that I should stop taking him outside because he might get hurt.

I used to go to church, but I stopped. This one time, my child released her waste [faeces] there in church and people all acted funny and left. So, I realized that I'd rather stop going to church than to always be worried when I go to church.

Furthermore, mothers feel people do not understand their daily life issues with their disabled child, and therefore opt to not talk about their situation - not even with good friends. Many mothers state that they have reverted to self-healing. Consequently, they end up having very limited social contacts.

In terms of medical support, in most instances, mothers initially try to find a 'cure' for their child's disability by visiting countless medical practitioners. However, they progressively choose to merely seek medical assistance (GP visits and over-the-counter medication) when their child is sick, and only at local clinics (the wider Khayelitsha area), due to transport and financial issues. Most specialized treatments such as speech therapy, physiotherapy and occupational therapy are situated far away from Khayelitsha and the majority of mothers attend such specialists once or twice on referral, often not attending later referrals. Mothers usually deem the costs of transport and time to access these medical services too high, even though public health care is generally free of charge in South Africa.

The other thing is the transport. I struggle to get him transport to the hospital. That stresses me. I try, I try. But if things are really difficult, I call the hospital and tell them that I can't make it for his appointment day because I don't have transport.

(Nceba)

Exceptions are sometimes made for follow-up appointments at the country' leading children's hospital, and for obtaining state-subsidized assistive devices. These are regarded as essential for their child's health. Mothers therefore put substantial effort into obtaining access such as by saving up for transport or asking for help from a neighbour who has a car.

Mothers' own health issues are also given low priority. Most mothers seldom see a doctor for - what they call - 'minor' issues such as constant headaches, lower back pain, allergies or painful joints. In fact, if they attend to their physical issues at all, they commonly resort to a local traditional healer.

Mandisa: There is a woman with the cure for it. I also went to her. I was in very bad pains. [...] She was a traditional healer.

Nomble: Did that person help you?

Mandisa: She did... I had a headache which was very painful. She only gave me one bottle of medicine... I had pains in my stomach and there was a very sharp pain in my heart... She told me that it was the pimples [cancer] that grew in my body.

Nomble: Were you not operated since you had the pimples?

Mandisa: No,... I was not operated,... I never agreed to that.

Unlike Mandisa who refused (western) medical attention altogether due to financial constraints, most mothers do seek medical advice for 'serious' health issues such as hypertension, depression and diabetes. Still, during informal conversations some mothers admit they take the long-term medication prescribed for these complaints intermittently, 
depending on the money available that month.

Minimizing their search for external support: consequences

As might be expected, mothers' tendency, in a context of discrimination, financial constraints and $24 / 7$ care, to minimize their social and medical relations has detrimental consequences. Their psychological and physical health is significantly affected. They have little rest time and there is minimal chance to offload the psychological burden by sharing with others. Nditoma, mother of a teenage boy, says: 'I am physically tired... I just long to rest and rest and rest so much'. Nceba shares her feelings: 'I have had this internal conflict for so long without anyone to talk to'.

\section{Minimizing their search for external support: benefits and trade-offs}

Despite the physical and psychological consequences, mothers indicate that saving time and money by minimally engaging with the 'outside' world allows for better child-care (without having to face abuse) and household maintenance, and ultimately self-respect. Most take great pleasure in managing daily home life and focusing on their child's hygiene and contentment. Akhona proudly recounts:

This other lady... came to my house and asked me, "Why are you forever with this child of yours?". I told her that I am always with my child because I love my child... and I don't see anyone I would share my experience with.

Thus, limiting their social activities and use of medical health care has certain benefits they value, namely freedom from abuse, good motherhood and self-respect, which often outweigh the detrimental consequences for their personal wellbeing. Naturally, the extent to which mothers adapt their social and medical relations varies, and there are cases where mothers want to seek medical attention but lack the means to do so. Nodende, who says she has to go back to the hospital for a new prescription for her daughter's infection, states: 'I don't have money to go back to the hospital, because in the last few months I got a disability grant, but now I didn't get it'. Nonetheless, mothers' tendency to retreat from the 'outside' world is seldom just an adaptation to unfavourable conditions, but rather a balancing act between social and medical needs, external circumstances and personal values.

\section{Minimizing their search for external support: mitigation}

Furthermore, all women attempt to mitigate the strenuous consequences for their own wellbeing of limited support and caring for their child, of which emaxhoseni is the most mentioned, meaning visiting their rural home, generally in the Eastern Cape of South Africa. This is time-consuming and costly (average 24-hour bus ride), yet vitally important for their wellbeing. Particularly during lunches and group activities, mothers often discuss their visits to their rural home. Going home is seen as an escape, a momentary break from the daily grind. Having close family members to care for their child enables mothers to offload some of the caring responsibility. In addition, for four mothers, going home is a way of legitimately, though temporarily, extricating themselves from spousal abuse. Lihle says:

I ran away after being beaten, back home... He beat me up for no reason. He made all sorts of accusations, so I took my child's grant money and went to the rural areas.

Their stories underscore the fact that for most women their rural home, though not easily accessible, is a safe space where they can relax, unwind and heal.

\section{Discussion}

This article aimed to show how mothers of children with a disability from a poor urban settlement in South Africa manoeuvre, adapt, act and react within their constrained daily context. This goes beyond the prevailing and stereotypical 'misery' narratives of mothers as poor, passive victims of circumstances. Recognizing and understanding mothers' agency and adaptation, we argue, is a vital part of amplifying grassroots women's voices and designing interventions and developing policies which suit their daily realities.

We adopted Khader's (2011) conceptualization of Adapted Preferences to be able to assess mothers' (sometimes deprivation-perpetuating) adaptation to a disadvantaged context, while simultaneously acknowledging their underlying values, reasoning and ultimately their agency. Mothers in Khayelitsha had two major preferences, namely keeping their child at home and minimizing their search for external support. We showed how these are based on forced trade-offs.

Our data analyses revealed several contextual factors which influence the trade-offs mothers make such as a lack of income, time constraints and living far away from services and (extended) family. The most important and striking factors, however, which force both tradeoffs are discrimination, violence and abuse in all life spheres, i.e. family, community, and institutions. Both APs mainly originate from mothers' strong desire to keep themselves and their child safe from any form of abuse or harm. Experienced or expected neglect and abuse at special schools, day-care centres and from private babysitters drive mothers to keep their child mainly indoors and provide 24/7 care. Likewise, the generally negative response from family, community members and strangers leads them to limit their social relations and focus on their household and care. The high volume and severity of violence, crime and disability discrimination in South Africa is well known (UNICEF, 2013), however, their influence on the agency of mothers with a disabled child have not explicitly been documented before. Similarly, the lack of social support many mothers with disabled children experience is widely recognized in previous research (Hemming \& Akhurst, 2009; McNally \& Mannan, 2013), yet women's deliberations and reasoning in this, and the trade-offs they make, are under-acknowledged.

Mothers are aware of the losses they will incur but also the benefits they stand to gain by isolating themselves and their child. Mothers' personal values are influential in this process. Both the high value they place on 'good motherhood' and their religious belief play a leading role in their deliberations and adaptation, as we showed in a previous article (). Women take great pride in being a good mother who raises a clean, well-fed, and safe child and in fulfilling their God-given duties. Even if achieving this requires sacrifices to be made in the domains of income, basic needs and personal wellbeing, most mothers in Khayelitsha prefer the former over the latter. Self-respect and social recognition are indeed the benefits mothers gain in return from these forced trade-offs, apart from the most important, namely freedom from (all forms of) violence.

The above findings support Khader's argument that the sole fact a woman has a self-depriving adaptive preference does not automatically render her to have a global deficit in self-entitlement or self-worth. In Khayelitsha, mothers' self-depriving preferences 'coexist with manifest positive attitudes toward the self and well-being' (Khader, 2011, 116). Even though their disadvantageous context restricts and determines their possibilities, they are flexible, active, and vigilant in addressing issues and sustaining or creating a life in accordance with their personal norms and values.

Nonetheless, the consequences of their context-bound preferences are pervasive. Not only do they exert a great impact at an individual level, e.g. income, basic needs, and physical health, but the broader costs, we argue, are equally problematic. First, these particular preferences reinforce gendered notions of care. In South Africa, women's social role is traditionally constructed along patriarchal lines. Women are mostly seen as the main care providers. In recent decades, women were slowly accepted into the paid workforce, providing them (partial) financial freedom, self-development and mobility (Mosoetsa, 2011), but our analysis shows that giving birth to a disabled child in a poor (violence-prone) urban settlement intensifies women's notion of 'good' motherhood and prompts them to retreat from public (work) life and (re)focus on their traditional role as a care and home provider. This 
mothering ideology limits women's self-development and self-determination, and reinforces oppressive patriarchal standards (Arendell, 2000).

Second, a harmful result of mothers' forced APs (isolation) is that they fall below the radar of policymakers. As these mothers prefer to manage their household and care responsibility in isolation - on the fringes of society - they become or remain invisible. As our data analyses show, mothers constantly adapt and react to daily life, and need to manoeuvre and prioritize to 'make it through a day'. This takes up tremendous amounts of time, effort and energy which cannot be invested in, for example, campaigning for better services. Consequently, the broader society hardly experiences any burden, and remains largely unaware of mothers' daily struggle and specific needs for (family) wellbeing. In fact, in terms of policy, whereas before there was a Ministry and Department of Women, Children and Disabilities which acknowledged the particular needs of these groups and their intersectionality, these were dissolved in 2014 (South African Government News Agency, 2014). Now a Ministry of Women focuses on women's empowerment and gender equality and a separate Ministry of Social Development aims to advance the rights of people with disabilities and children. Addressing the multiple interlocking disadvantages these women face, i.e. gender norms, care, disability and poverty, thus becomes considerably more difficult.

In light of our findings, public interventions in the lives of these women and their children should be based on a critical awareness of how discrimination and abuse are the driving external forces behind mothers' adaptive preferences whereas good motherhood and religion are the main internal motivators. Moreover, the necessary trade-offs mothers make need to be well understood. Without understanding these crucial factors, public interventions run a profound risk of being misguided and unsuccessful, e.g. economic empowerment programmes without high-quality specialized day-care would be ineffective as mothers would prefer to keep their child at home and not participate. Conscientization about gender equality and care would probably fall flat since mothers both highly value motherhood and would not let others care for their child as long as they suspect harmful practices.

We argue, therefore, that the first priority should lie with eradicating the forces that shape these preferences, i.e. disability discrimination, violence and abuse. Family training on disability and care, providing for high-quality specialized day-care facilities with trained professionals, and raising community awareness on disability, are but a few examples of interventions that could provide room for mothers to share the care responsibility. Indeed, changing the disadvantageous social and institutional conditions that force a mother's preferences might set off a change in adaptation and agency, thereby nourishing their child's and their own wellbeing.

\section{Limitations}

Given our chosen method of sampling via a care-centre, and the particular Khayelitsha context, our research findings cannot be extrapolated to all South African women with a disabled child as they are relational, narrative and specific. We cannot determine whether agency and adaptation play out differently for women who chose not to participate in our project, and in particular for women who are so isolated they are not engaged with services or known to care for a disabled child by others in the wider community. More research from resource-poor areas on mothers of disabled children would diversify the findings on the 'how and why' of women's adaptation and agency. In addition, the collective and the action-oriented character of the project, and the presence of familiar translators might have skewed the answers of the mothers to fit the social context or anticipated projects. Yet, considering it was a long-term project with continued observation and triangulation of methods, we believe this risk was substantially reduced. Lastly, researcher bias due to the main researcher's white, western background might have influenced topic selection, oral or behavioural responses and chosen questions. To reduce this as much as possible, continued reflection was pursued through shared analysis with the participants, enlisted experts, and research group.

\section{Conclusion}

This study highlights adaptation and agency of mothers from Khayelitsha caring for a disabled child by showing how they manoeuvre, adapt, act and react within their daily constraints. Their two main adaptive preferences, i.e. keeping their child at home and minimizing their search for external support, are predominantly forced by discrimination and abuse in the wider community and based on tradeoffs. Personal values regarding being a good mother and Christian as well as benefits such as self-respect, social recognition and freedom from (all forms of) violence motivate mothers to make sacrifices in terms of income, basic needs and personal wellbeing.

The problematic consequences of the resulting isolation are that it reinforces patriarchal standards of care and renders the women and their children invisible to policymakers and society at large. We argue that for interventions to be successful, the first priority should be to eradicate the forces behind these adaptive preferences, which are discrimination, violence and abuse. Changing these conditions while taking into account mothers' personal values and preferences might provide room for these mothers to adapt and act in more self-beneficial ways, and so improve their own and their child's wellbeing.

\section{Acknowledgements}

This project has been funded with support of the European Commission. This publication reflects the view only of the author, and the Commission cannot be held responsible for any use which may be made of the information contained therein. The European Commission has not had any involvement in study design.

\section{Declaration of competing interest}

None

\section{References}

Ahearn, L. M. (2000). Agency. Journal of Linguistic Anthropology, 9(1-2), 12-15.

Alkire, S. (2008). Concepts and measures of agency. OPHI working paper series no. 9 Oxford Poverty \& Human Development Initiative (OPHI). Oxford: OPHI, University of Oxford.

Arendell, T. (2000). Conceiving and investigating motherhood: The decade's scholarship. Journal of Marriage and Family, 62(4), 1192-1207.

Beresford, P. (2016). Presenting welfare reform: Poverty porn, telling sad stories or achieving change? Disability \& Society, 31(3), 421-425. https://doi.org/10.1080/ 09687599.2016.1173419.

Brunn, S. D., \& Wilson, M. W. (2012). Cape Town's million plus black township of Khayelitsha: Terrae incognitae and the geographies and cartographies of silence. Habitat International, 39, 284-294. https://doi.org/10.1016/j.habitatint.2012.10. 017.

Conradie, I. (2014). Aspirations and capabilities: The design and analysis of an action research project in Khayelitsha, Cape Town. Unpublished PhD-thesisCape Town: University of the Western Cape.

DSD (2016). White paper on the rights of persons with disabilities. Pretoria: Department of Social Development, Republic of South Africa.

DSD, DWCPD, \& UNICEF (2012). Children with disabilities in South Africa: A situation analysis: 2001-2011. Pretoria: Department of Social Development/Department of Women, Children and People with Disabilities/UNICEF.

Elster, J. (1987). Sour grapes: Studies in the subversion of rationality. Cambridge: Cambridge U.P.

Geertz, C. (1973). The interpretation of cultures: Selected essays. New York: Basic Books.

Hartley, S. O. V. P., Ojwang, P., Baguwemu, A., Ddamulira, M., \& Chavuta, A. (2005) How do carers of disabled children cope? The Ugandan perspective. Child: Care, Health and Development, 31(2), 167-180. https://doi.org/10.1111/j.1365-2214.2004. 00464.x.

Hemming, E., \& Akhurst, J. (2009). Mothers' life-worlds in a developing context when a child has special needs. Indo-Pacific Journal of Phenomenology, 9(1), 1-12. https://doi. org/10.1080/20797222.2009.11433988.

Huiracocha-Tutiven, L., Orellana-Paucar, A., Brito, L., \& Blume, S. (2017). Parents and grandparents of deaf children in Ecuador: Concerns and expectations. Disability \& 
Society, 32(10), 1555-1569.

Khader, S. J. (2011). Adaptive preferences and Women's empowerment. New York: Oxford U.P.

Khader, S. J. (2013). Identifying adaptive preferences in practice: Lessons from postcolonial feminisms. Journal of Global Ethics, 9(3), 311-327.

Khanlou, N., \& Peter, E. (2005). Participatory action research: Considerations for ethical review. Social Science \& Medicine, 60(10), 2333-2340.

Mathye, D., \& Eksteen, C. (2015). Investigation of challenges experienced by caregivers of children with disability in rural South Africa: Caregivers and rehabilitation professionals' perspectives. Physiotherapy, 101, eS961. https://doi.org/10.1016/j.physio. 2015.03.1815.

Matt, S. B. (2014). Perceptions of disability among parents of children with disabilities in Nicaragua: Implications for future opportunities and health care access. Disability Studies Quarterly, 34(4), https://doi.org/10.18061/dsq.v34i4.3863 online.

McNally, A., \& Mannan, H. (2013). Perceptions of caring for children with disabilities: Experiences from Moshi, Tanzania. African Journal of Disability, 2(1), 1-10. https:// doi.org/10.4102/ajod.v2i1.21.

Minkler, M., Fadem, P., Perry, M., Blum, K., Moore, L., \& Rogers, J. (2002). Ethical dilemmas in participatory action research: A case study from the disability community. Health Education \& Behavior, 29(1), 14-29. https://doi.org/10.1177/ 109019810202900104.

Mosoetsa, S. (2011). Eating from one pot. The dynamics of survival in poor South African households. Johannesburg: Wits University Press.

Nussbaum, M. C. (2001). Women and human development: The capabilities approach. Cambridge: Cambridge University Press.

Philpott, S., \& McLaren, P. (2011). Hearing the voices of children and caregivers: Children with disabilities in South Africa. A situation analysis, 2001-2011. Pretoria: Department of Social Development, Republic of South Africa/UNICEF.

Pretorius, C., \& Steadman, J. (2017). Barriers and facilitators to caring for a child with cerebral palsy in rural communities of the Western Cape, South Africa. Child Care in Practice, 1-18. https://doi.org/10.1080/13575279.2017.1347146.

Qayyum, A., Lasi, S. Z., \& Rafique, G. (2013). Perceptions of primary caregivers of children with disabilities in two communities from Sindh and Balochistan, Pakistan. Disability, CBR \& Inclusive Development, 24(1), 130-142. https://doi.org/10.5463/ DCID.v24i1.193.

Saloojee, G., Phohole, M., Saloojee, H., \& Ijsselmuiden, C. (2007). Unmet health, welfare and educational needs of disabled children in an impoverished South African peri- urban township. Child: Care, Health and Development, 33(3), 230-235. https://doi. org/10.1111/j.1365-2214.2006.00645.x.

Sandy, P. T., Kgole, J. C., \& Mavundla, T. R. (2013). Support needs of caregivers: Case studies in South Africa. International Nursing Review, 60(3), 344-350. https://doi.org/ 10.1111/inr.12022.

SASSA (2016). South African Social Security Agency: Care dependency grant. http:// www.sassa.gov.za/index.php/social-grants/care-dependency-grant, Accessed date: 24 April 2017.

Seekings, J. (2010). Race, class and inequality in the South African City. Cape Town: Centre for Social Science Research.

Seekings, J. (2013). Economy, society and municipal services in Khayelitsha. Cape Town: Centre for Social Science Research, University of Cape Town.

Seekings, J., \& Nattrass, N. (2015). Policy, politics and poverty in South Africa. Basingstoke: Palgrave Macmillan.

Sen, A. (1988). On ethics and economics. Malden, MA: Blackwell.

South African Government News Agency (2014). President announces new cabinet. https://www.sanews.gov.za/south-africa/president-announces-new-cabinet, Accessed date: 15 March 2018.

STATS SA (2015). Methodological report on rebasing of national poverty lines and development of pilot provincial poverty lines. Pretoria: Statistics South Africa.

Super, G. (2015). Violence and democracy in Khayelitsha. Governing crime through the 'community'. Stability: International Journal of Security and Development, 4(1), 1-20.

Taderera, C., \& Hall, H. (2017). Challenges faced by parents of children with learning disabilities in Opuwo, Namibia. African Journal of Disability, 6(1), 1-10.

Terlazzo, R. (2016). Conceptualizing adaptive preferences respectfully: An indirectly substantive account. Journal of Political Philosophy, 24(2), 206-226.

UNICEF (2013). The state of the world's children 2013. Children with disabilities. New York: United Nations Children's Fund.

Van der Mark, E. J., Conradie, I., Dedding, C. W. M., \& Broerse, J. E. W. (2017). How poverty shapes caring for a disabled child: A narrative literature review. Journal of International Development, 29(8), 1187-1206. https://doi.org/10.1002/jid.3308.

der Mark, Van (2018). We Create Our Own Small World': Daily Realities of Mothers of Disabled Children in a South African Urban Settlement. Disability \& Society, 34.

Wijesinghe, C. J., Cunningham, N., Fonseka, P., Hewage, C. G., \& Østbye, T. (2015) Factors associated with caregiver burden among caregivers of children with cerebral palsy in Sri Lanka. Asia-Pacific Journal of Public Health, 27(1), 85-95. https://doi.org/ $10.1177 / 1010539514548756$. 